\title{
Correlation of the Rates of Solvolysis of $t$-Butyl Fluoroformate Using the Extended Grunwald-Winstein Equation
}

\author{
Yong-Woo Lee, Mi Hye Seong, Jin Burm Kyong, ${ }^{*}$ and Dennis N. Kevill ${ }^{\dagger}$ \\ Department of Chemistry and Applied Chemistry, Hanyang University, Ansan-si, Gyeonggi-do 426-791, Korea \\ *E-mail: jbkyong@hanyang.ac.kr \\ ${ }^{\dagger}$ Department of Chemistry and Biochemistry, Northern Illinois University, DeKalb, Illinois 60115-2862, U.S.A. \\ Received September 8, 2010, Accepted September 15, 2010
}

\begin{abstract}
The specific rates of solvolysis of $t$-butyl fluoroformate (1) have been measured at $40.0{ }^{\circ} \mathrm{C}$ in 21 pure and binary solvents. These give a satisfactory correlation over the full range of solvents when the extended Grunwald-Winstein equation, with incorporation of the solvent nucleophilicity and the solvent ionizing power, is applied. The actual values are very similar to those obtained in earlier studies of the solvolyses of isopropyl chloroformate and ethyl chlorothioformate in the more ionizing and least nucleophilic solvents, which are believed to proceed by an ionization pathway. The small negative values for the entropies of activation are consistent with the ionization nature of the proposed rate-determining step. These observations are also compared with those previously reported for the corresponding primary and secondary alkyl haloformate esters.
\end{abstract}

Key Words: $t$-Butyl fluoroformate, Grunwald-Winstein equation, Alkyl haloformate esters, Ionization pathway

\section{Introduction}

In previous studies concerning the application of the Grunwald-Winstein equations to the specific rates of solvolysis of primary and secondary alkyl haloformate esters, ${ }^{1}$ we have discussed correlations with incorporation of the solvent nucleophilicity scale and the solvent ionizing power scale, and have proposed reaction mechanisms. The simple (one-term) Grunwald-Winstein equation [eqn. (1)] has been employed as very useful mechanistic tool for solvolysis reactions. ${ }^{2}$

$$
\log \left(k / k_{o}\right)=m Y
$$

In eqn. $1, k$ and $k_{o}$ represent the specific rates of solvolysis in the solvent under consideration and in $80 \%$ ethanol, respectively, $m$ represents the sensitivity to changes in solvent ionizing power $(Y)$. The equation (1) can be taken as one indicator of mechanism. Accordingly, determination of the $m$ values will be a valuable source of information concerning the structure of the transition state for these solvolyses.

The Grunwald-Winstein equation [eqn. (1)] was proposed in 1948 for the correlation of solvolysis reactions proceeding by an ionization pathway, with rate-determining formation of a carbocation and its fast subsequent substitution or, when possible, elimination reaction. The original standard substrate, $t$-butyl chloride, ${ }^{2}$ has been replaced by 1 -adamantyl chloride and either 1- or 2-adamantyl derivatives have been used to set up a series of $Y_{\mathrm{x}}$ scales for the $\mathrm{X}$ leaving group. ${ }^{3,4}$ Since, with both substrates, for elimination reaction, a double bond would develop at the bridgehead, which is energetically disfavored (Bredt's Rule), ${ }^{4}$ only substitution product is observed. For a bimolecular mechanism, the correlation is extended to the (two-term) GrunwaldWinstein equation [eqn. (2)], with addition of a term governed by the sensitivity $(l)$ to changes in solvent nucleophilicity $(N)$.

$$
\log \left(k / k_{o}\right)=l N+m Y
$$

Bentley and co-worker initially used methyl tosylate as the standard substrate $\left(N_{\mathrm{OTs}}\right.$ scale) ${ }^{5}$ More recently, $N_{\mathrm{T}}$ scales based on the solvolyses of the $S$-methyldibenzothiophenium ion (Me$\left.\mathrm{DBTh}^{+}\right)^{6,7}$ have been developed, in which the leaving group is a neutral molecule, which is little influenced by solvent change. The $N_{\mathrm{T}}$ values have been become the recognized standards for considerations of solvent nucleophilicity. The magnitudes of the $l$ and $m$ values can give important indications regarding the mechanism of solvolysis. In the equation (2), the sensitivity $(l)$ to changes in solvent nucleophilicity $\left(N_{\mathrm{T}}\right.$ or $\left.N_{\text {OTS }}\right)$ falls from a value of about 0.4 to zero as steric hindrance (tertiary alkyl halides) is increased. ${ }^{8}$

The solvolyses of methyl fluoroformate, $\mathrm{MeOCOF}^{1(\mathrm{~b})}$ and methyl chloroformate, $\mathrm{MeOCOCl}^{1(\mathrm{a})}$ (primary alkyl haloformate esters), and isopropyl fluoroformate, $i$-PrOCOF ${ }^{1(\mathrm{~d})}$ (secondary alkyl haloformate ester) proceed predominantly by an additionelimination pathway, with the addition step being rate-determining (Scheme 1). Only in solvents of very low nucleophilicity and very high ionizing power (for example, $\mathrm{MeOCOCl}$ in $90 \%$ 1,1,1,3,3,3-hexafluoro-2-propanol, HFIP) can an ionization pathway be detected. Unlike the reactions in hydroxylic solvents of $n$-propyl fluoroformate, $i$-PrOCOF, where only addition-elimination pathway was observed, the solvolyses of $i$-PrOCOCl ${ }^{1(\mathrm{c})}$ have two major reaction pathways: an addition-elimination pathway involving substitution at acyl carbon in the more nucleophilic solvents (Scheme 1) and an ionization pathway involving the loss of carbon dioxide accompanying the substitution in

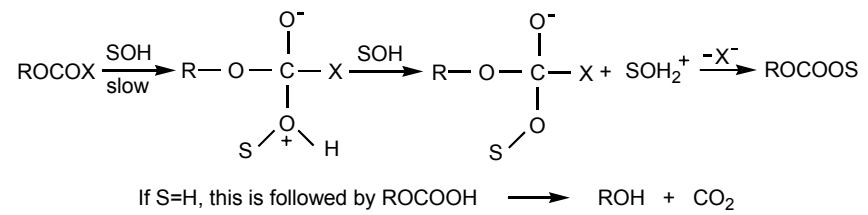

Scheme 1. Addition-elimination pathway 


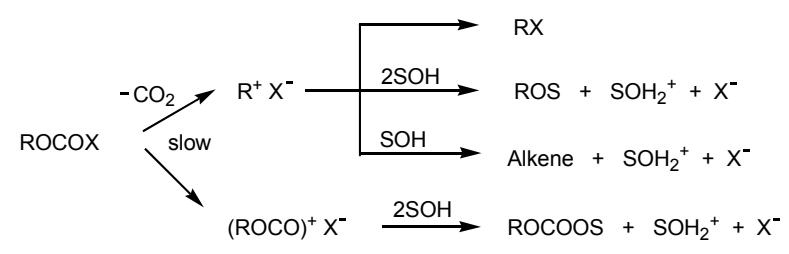

Scheme 2. Ionization pathway

the more ionizing solvents (Scheme 2). ${ }^{1}$ In some instances, the pathway involving the loss of carbon dioxide can also exhibit an elimination component, leading to alkene. In the solvolyses of the tertiary 1-adamantyl chloroformate (1-AdOCOCl), ${ }^{1(e)}$ only in $100 \%$ ethanol was a trace of a product with retention of carbon dioxide observed, and the kinetics and products could be interpreted in terms of solvolysis-decomposition, proceeding through the relatively stable 1-adamantyl cation (Scheme 2). The corresponding 1-adamantyl fluoroformate $(1-\mathrm{AdOCOF})^{1(f)}$ showed a very much reduced tendency toward ionization and only in highly ionizing solvents of low nucleophilicity does the behavior parallel to that of the chloroformate. In other solvents, the solvolyses of 1-AdOCOF proceed predominantly by an addition-elimination pathway, with the addition step being ratedetermining (Scheme 1).

An interesting substrate for consideration of the simplest tertiary type would be a tert-butyl haloformate ester. In the present study, we report on the specific rates for solvolyses of tert-butyl fluoroformate $(t$-BuOCOF, 1) in a variety of pure and binary solvents. The corresponding chloro-compound, tert-butyl chloroformate $(t-\mathrm{BuOCOCl})^{9}$ decomposes rapidly and cannot be conveniently studied. The results are also discussed in terms of the sensitivity $(l)$ to changes in solvent nucleophilicity $\left(N_{\mathrm{T}}\right)$ and the sensitivities $(m)$ toward change in solvent ionizing power $\left(Y_{\mathrm{Cl}}\right)$. In addition to the application of the simple and extended Grunwald-Winstein equations to the specific rates, the influence of temperature on the specific rate allows enthalpies and entropies of activation to be calculated. This is the first time that the extended Grunwald-Winstein equation (2) has been used as a tool in studies of $t$-BuOCOF (1) solvolysis. Moreover, since both 1 and 1-AdOCOF are tertiary alkyl haloformate esters, mechanistic similarities would be expected. Accordingly, the findings for solvolyses of $\mathbf{1}$ are compared with those reported previously for primary, secondary, and tertiary alkyl haloformate esters.

\section{Results and Discussion}

The specific rates of solvolysis of tert-butyl fluoroformate (1) at $40.0^{\circ} \mathrm{C}$ were determined in ethanol and methanol and in binary mixtures of water with ethanol (EtOH), methanol $(\mathrm{MeOH})$, acetone, and 2,2,2-trifluoroethanol (TFE). Specific rates were also determined in four binary mixtures of 2,2,2-trifluoroethanol and ethanol (T-E). The specific rates of solvolysis are presented in Table 1, together with $N_{\mathrm{T}}^{6}$ and $Y_{\mathrm{Cl}}^{3,4}$ values. A determination was also made in methanol- $d$ (MeOD). For methanol, ethanol, $80 \% \mathrm{EtOH}$, and $70 \%$ TFE, specific rates of solvolysis of $\mathbf{1}$ were determined at three additional temperatures, and these values, together with calculated enthalpies and entropies of acti-
Table 1. Specific rates of solvolysis of $t$-butyl fluoroformate (1) in a variety of pure and mixed solvents at $40.0{ }^{\circ} \mathrm{C}$ and the $N_{T}$, and $\boldsymbol{Y}_{C l}$ values for the solvents

\begin{tabular}{cccc}
\hline Solvent $^{a}$ & $10^{4} k\left(\mathrm{~s}^{-1}\right)^{b}$ & $N_{T}{ }^{c}$ & $Y_{C l}{ }^{d}$ \\
\hline $100 \% \mathrm{MeOH}$ & $0.528 \pm 0.019^{f,}$ & 0.17 & -1.17 \\
$90 \% \mathrm{MeOH}$ & $2.29 \pm 0.07$ & -0.01 & -0.18 \\
$80 \% \mathrm{MeOH}$ & $7.76 \pm 0.40$ & -0.06 & 0.67 \\
$70 \% \mathrm{MeOH}$ & $21.5 \pm 0.9$ & -0.40 & 1.46 \\
$100 \% \mathrm{EtOH}$ & $0.0934 \pm 0.0031$ & 0.37 & -2.52 \\
$90 \% \mathrm{EtOH}$ & $0.820 \pm 0.016$ & 0.16 & -0.94 \\
$80 \% \mathrm{EtOH}$ & $3.69 \pm 0.01$ & 0.00 & 0.00 \\
$70 \% \mathrm{EtOH}$ & $11.7 \pm 0.2$ & -0.20 & 0.78 \\
$60 \% \mathrm{EtOH}$ & $26.5 \pm 0.5$ & -0.38 & 1.38 \\
$90 \% \mathrm{Acetone}$ & $0.136 \pm 0.008$ & -0.35 & -2.22 \\
$80 \% \mathrm{Acetone}$ & $1.12 \pm 0.06$ & -0.37 & -0.83 \\
$70 \% \mathrm{Acetone}$ & $5.27 \pm 0.19$ & -0.42 & 0.17 \\
$60 \% \mathrm{Acetone}$ & $16.0 \pm 0.6$ & -0.52 & 0.95 \\
$97 \% \mathrm{TFE}$ & $13.0 \pm 0.4$ & -3.30 & 2.83 \\
$90 \% \mathrm{TFE}$ & $17.6 \pm 0.7$ & -2.55 & 2.85 \\
$70 \% \mathrm{TFE}$ & $37.1 \pm 0.4$ & -1.98 & 2.96 \\
$50 \% \mathrm{TFE}$ & $105 \pm 2$ & -1.73 & 3.16 \\
$80 \mathrm{~T}-20 \mathrm{E}^{e}$ & $1.94 \pm 0.04$ & -1.76 & 1.89 \\
$60 \mathrm{~T}-40 \mathrm{E}^{e}$ & $0.790 \pm 0.010$ & -0.94 & 0.63 \\
$40 \mathrm{~T}-60 \mathrm{E}^{e}$ & $0.426 \pm 0.019$ & -0.34 & -0.48 \\
$20 \mathrm{~T}-80 \mathrm{E}^{e}$ & $0.186 \pm 0.008$ & 0.08 & -1.42
\end{tabular}

${ }^{a}$ Volume/volume basis at $25.0{ }^{\circ} \mathrm{C}$, except for TFE- $\mathrm{H}_{2} \mathrm{O}$ mixtures, which are on a weight/weight basis. ${ }^{b}$ With associated standard deviation. ${ }^{c}$ From refs. 6 and 7. ${ }^{d}$ From refs. 3 and $4 .{ }^{e}$ T-E are 2,2,2-trifluoroethanol-ethanol mixtures. ${ }^{f}$ Value in MeOD of $0.420 \pm 0.008$, and solvent deuterium isotope effect $\left(k_{\mathrm{MeOH}} / k_{\mathrm{MeOD}}\right)$ of $1.26 \pm 0.02$.

vation, are reported in Table 2.

In Table 1, the specific rates for the solvolysis of 1 increase with increasing the ionizing power $Y$-value in all the solvents studied, i.e., the specific rates of solvolysis of $\mathbf{1}$ increase from $0.0934 \times 10^{-4} \mathrm{~s}^{-1}$ in $100 \% \mathrm{EtOH}(Y$-value $=-2.52)$ to $105 \times 10^{-4}$ $\mathrm{s}^{-1}$ in 50\% TFE $(Y$-value $=3.16)$. This means that the reaction rate is a strong dependence on solvent polarity, suggesting that bond breaking in transition state is mechanistically importance. These phenomena are similar to those previously studied for $i$-propyl chloroformate $(i \text {-PrOCOCl })^{1(c)}$ and ethyl chlorothioformate $(\mathrm{EtSCOCl})^{1(\mathrm{~g})}$ in all the solvents, except the less ionizing and more nucleophilic solvents, which are believed to proceed by an ionization pathway.

Comparing the specific rates of $\mathbf{1}$ with those previously reported for $\mathrm{MeOCOF}^{1(\mathrm{~b})}$ and $i$-PrOCOF ${ }^{1(\mathrm{~d})}$ in $100 \%, 80 \% \mathrm{EtOH}$ and $100 \% \mathrm{MeOH}$ at $40.0^{\circ} \mathrm{C}$, we observe a rate trend of $k_{\text {MeOCOF }}>$ $k_{i-P r O C O F} \geq k_{t-B u O C O F}$. This signals that the inductive effect exerted by the alkoxy groups and/or the mesomeric effect in alkyl haloformates make the carbonyl carbon more positive. Also the $1-\mathrm{AdOCOF}^{1(\mathrm{ff})} / t$-BuOCOF rate ratios $\left(k_{1-A d O C O F} / k_{t-B u O C O F}\right)$ vary from $c a$. $(5.8 \sim 7.2) \times 10^{-3}$ times in $100 \%, 80 \% \mathrm{EtOH}$ and $100 \% \mathrm{MeOH}$ to $c a .0 .1$ times in $70 \%$ TFE. These values are similar to the ones observed for the 1-adamantyl and $t$-butyl chlorides demonstrated to solvolyze in all the solvents with ionization pathway $\left(k_{l-A d C l} / k_{t-B u C l} \fallingdotseq \sim 10^{-3}\right.$ in $100 \% \mathrm{EtOH}$ and $80 \%$ EtOH, and $k_{1-A d C l} k_{t-B u C l} \fallingdotseq 0.3$ in $97 \%$ hexafluoroiso- 
propyl alcohol). ${ }^{3(\mathrm{a}), 4}$ The difference between the reactivity of 1-AdOCOF and $\mathbf{1}$ appears to be largely due to angle strain in the somewhat flattened but not planar transition states of the former substrate. This phenomenon was previously discussed by Bentley $^{3(a)}$ and Schleyer, ${ }^{4}$ and it will not be considered again in this type.

For solvolyses in ethanol, methanol, $80 \%$ ethanol, and $70 \%$ TFE, the values of the enthalpy and the entropy of activation for the solvolysis of 1 (Table 2) are $19.7 \sim 23.8 \mathrm{kcal} \mathrm{mol}^{-1}$ and $-2.8 \sim-6.7 \mathrm{cal} \mathrm{mol}^{-1} \mathrm{~K}^{-1}$, respectively. For the solvolyses studied kinetically as a function of temperature, the activation parameters of Table 3 are consistent with a duality of mechanism: the ionization pathway for solvolyses of $1-\mathrm{AdOCOF}^{1(\mathrm{f})}$ in $97 \% \mathrm{TFE}$ and $80 \%$ HFIP, and the addition-elimination pathway involving bimolecular attack by solvent at acyl carbon $\left(\mathrm{MeOCOF}^{1(\mathrm{~b})}\right.$ and $i$-PrOCOF ${ }^{1(\mathrm{~d})}$ in four solvents and $1-\mathrm{AdOCOF}^{1(\mathrm{f})}$ in $100 \%, 80 \%$ EtOH and $100 \% \mathrm{MeOH})$. The entropies of activation for the solvolysis of 1 , in the range of -2.8 to $-6.7 \mathrm{cal} \mathrm{mol}^{-1} \mathrm{~K}^{-1}$, are similar to those of considered to reflect the ionization channel

Table 2. Specific rates of solvolysis of $t$-butyl fluoroformate (1) at various temperatures and enthalpies $\left(\Delta H^{*}, \mathrm{kcal} \mathrm{mol}^{-1}\right)$ and entropies $\left(\Delta S^{\sharp}\right.$, cal $\left.\mathrm{mol}^{-1} \mathrm{~K}^{-1}\right)$ of activation

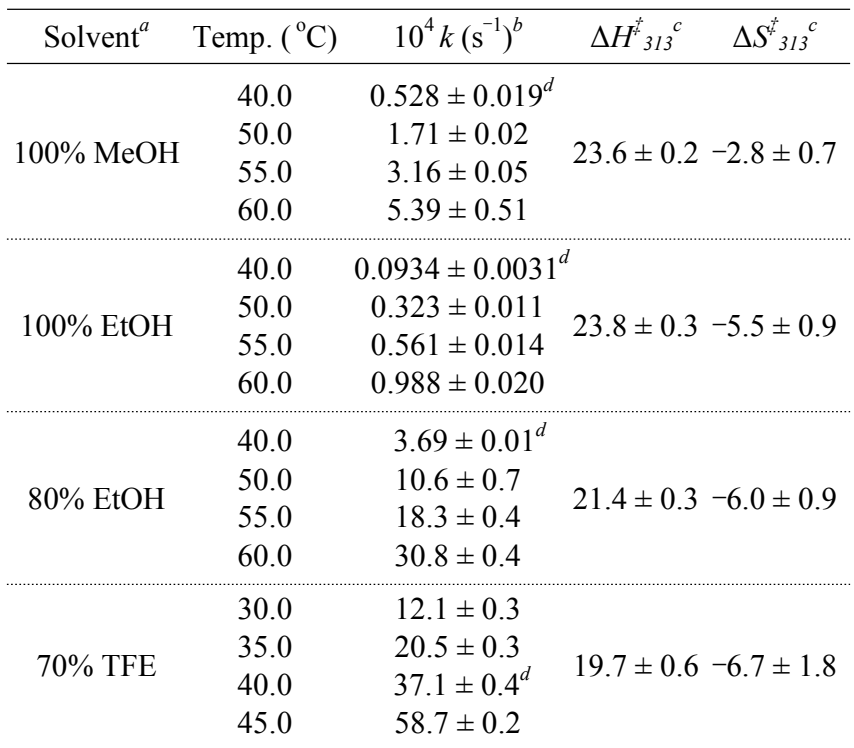

${ }^{a, b}$ See footnotes Table $1 .{ }^{c}$ With associated standard error. ${ }^{d}$ From Table 1. within the analyses of the solvolyses of 1-AdOCOF (-8.0 and $-9.3 \mathrm{cal} \mathrm{mol}^{-1} \mathrm{~K}^{-1}$ ) in $97 \%$ TFE and $80 \%$ HFIP solvents (Table 3 ) and $t$-butyl chloride $\left(-6.6 \mathrm{cal} \mathrm{mol}^{-1} \mathrm{~K}^{-1}\right)$ in $80 \% \mathrm{EtOH}$ at $25^{\circ} \mathrm{C}$.

The solvent deuterium isotope effect has previously been studied for several solvolyses of haloformate esters. In methanol, the $k_{\mathrm{MeOH}} / k_{\mathrm{MeOD}}$ ratio was in the range of 2.10 to 3.98 for phenyl chloroformate $(\mathrm{PhOCOCl}),{ }^{11} \mathrm{MeOCOF},{ }^{1(\mathrm{~b})}$ and $i$-PrOCOF ${ }^{1(\mathrm{~d})}$ believed to react by the bimolecular mechanism (Table 3 ). The value for $i$-PrOCOCl, ${ }^{1(\mathrm{c}), 9}$ in the ionization range, was somewhat lower at 1.25 in pure water and the value for diphenylcarbamoyl chloride was lower again at 1.1. ${ }^{12}$ The value for methanolysis of 1 of $k_{\mathrm{MeOH}} / k_{\mathrm{MeOD}}=1.26$ is similar to a solvent isotope effect value for unimolecular pathway of $i$-PrOCOCl (footnote Table 3 ). ${ }^{10}$

A powerful test in considering detailed mechanisms of solvolysis is to carry out a correlation analysis using the GrunwaldWinstein equation (eqns. 1 and 2). For 21 of the solvents for which specific rates of solvolysis of $\mathbf{1}$ are reported, both $N_{\mathrm{T}}$ and $Y_{\mathrm{Cl}}$ values are available (listed in Table 1). An analysis of the data using the simple Grunwald-Winstein equation (eqn. 1) to

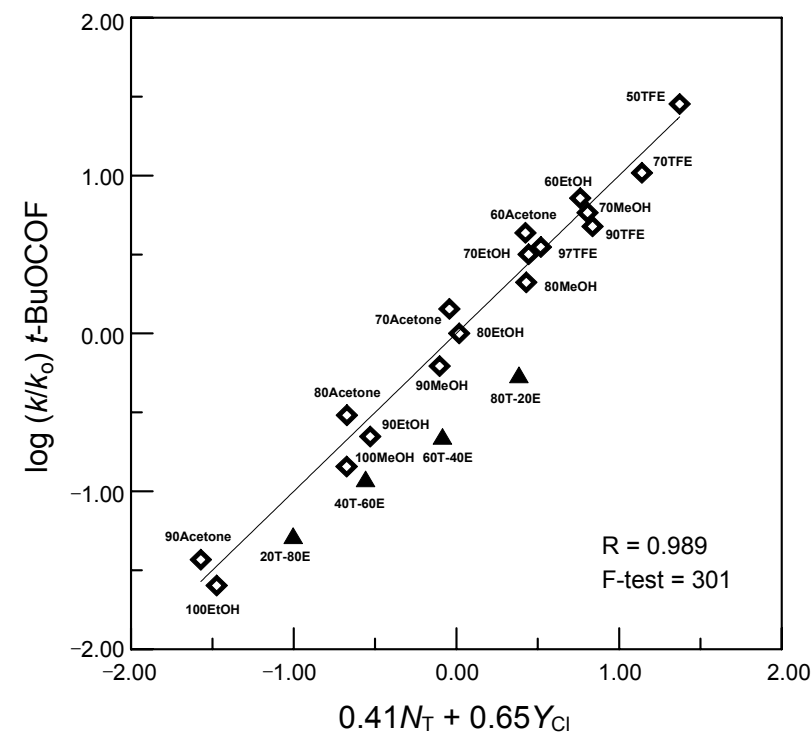

Figure 1. Plot of $\log \left(k / k_{o}\right)$ for solvolyses of $t$-butyl fluoroformate (1) against $\left(0.41 N_{\mathrm{T}}+0.65 Y_{\mathrm{Cl}}\right)$. The $\log \left(k / k_{o}\right)$ values for the four TFEEtOH mixtures are not included in the correlation; they are added to show their moderate deviation from the correlation line.

Table 3. Enthalpies $\left(\mathrm{kcal} \mathrm{mol}^{-1}\right)$ and entropies $\left(\mathrm{cal} \mathrm{mol}^{-1} \mathrm{~K}^{-1}\right)$ of activation for solvolysis reactions of alkyl haloformates and the solvent deuterium isotope effect $\left(k_{\mathrm{MeOH}} / k_{\mathrm{MeOD}}\right)$ at $40.0^{\circ} \mathrm{C}$

\begin{tabular}{|c|c|c|c|c|c|c|c|c|}
\hline \multirow{2}{*}{ Solvent $^{a}$} & \multicolumn{2}{|c|}{$\mathrm{MeOCOF}^{b}$} & \multicolumn{2}{|c|}{$i-\mathrm{PrOCOF}^{c}$} & \multicolumn{2}{|c|}{$t-\mathrm{BuOCOF}^{d}$} & \multicolumn{2}{|c|}{$1-\mathrm{AdOCOF}^{e}$} \\
\hline & $\Delta H^{t}$ & $\Delta S^{t}$ & $\Delta H^{*}$ & $\Delta S^{\hbar}$ & $\Delta H^{+}$ & $\Delta S^{t}$ & $\Delta H^{t}$ & $\Delta S^{*}$ \\
\hline $100 \% \mathrm{EtOH}$ & 11.0 & -39.8 & 11.3 & -45.5 & 23.8 & -5.5 & 16.8 & -32.7 \\
\hline $80 \% \mathrm{EtOH}$ & 9.1 & -38.9 & 9.5 & -43.9 & 21.4 & -6.0 & 12.6 & -38.5 \\
\hline $100 \% \mathrm{MeOH}$ & 8.9 & -38.7 & 11.7 & -40.8 & 23.6 & -2.8 & 13.8 & -38.0 \\
\hline $70 \%$ TFE & 9.9 & -39.0 & 14.0 & -32.8 & 19.7 & -6.7 & $21.7^{f}$ & $-8.0^{f}$ \\
\hline $80 \%$ HFIP $^{g}$ & - & - & - & - & - & - & 19.4 & -9.3 \\
\hline$k_{\mathrm{MeOH}} / k_{\mathrm{MeOD}}$ & \multicolumn{2}{|c|}{$3.98^{b}$} & \multicolumn{2}{|c|}{$2.53^{c, h}$} & \multicolumn{2}{|c|}{1.26} & \multicolumn{2}{|c|}{-} \\
\hline
\end{tabular}

${ }^{a}$ See footnotes Table $1 .{ }^{b}$ From ref. 1(b). ${ }^{c}$ From ref. 1(d). ${ }^{d}$ This study. ${ }^{e}$ From ref. 1(f). ${ }^{f}$ Values in 97\% TFE. ${ }^{g}$ On weight-weight basis, HFIP is 1,1,1,3,3,3hexafluoro-2-propanol. ${ }^{h}$ Solvent deuterium isotope effect $\left(k_{\mathrm{H}_{2} \mathrm{O}} / k_{\mathrm{D}_{2} \mathrm{O}}=1.25\right)$ for hydrolysis of $i$ - $\mathrm{PrOCOCl}$ (ref. 10). 
Table 4. Correlation of the specific rates of solvolysis of $t$-butyl fluoroformate (1) and a comparison with the corresponding values for the solvolyses of other haloformate esters using the extended Grunwald-Winstein equation

\begin{tabular}{|c|c|c|c|c|c|c|c|c|}
\hline Substrate & Mech. $^{a}$ & $n^{b}$ & $l^{c}$ & $m^{c}$ & $c^{c, o}$ & $\mathrm{R}^{d}$ & $F^{e}$ & $l / m$ \\
\hline $\mathrm{MeOCOF}$ & A-E & $14^{f}$ & $1.33 \pm 0.09$ & $0.73 \pm 0.06$ & $-0.08 \pm 0.08$ & 0.972 & 93 & 1.82 \\
\hline $\mathrm{MeOCOCl}$ & A-E & $19^{g}$ & $1.59 \pm 0.09$ & $0.58 \pm 0.05$ & $0.16 \pm 0.07$ & 0.977 & 171 & 2.74 \\
\hline$i$-PrOCOF & A-E & $20^{h}$ & $1.59 \pm 0.16$ & $0.80 \pm 0.06$ & $-0.12 \pm 0.05$ & 0.957 & 93 & 1.99 \\
\hline$i$-PrOCOCl & I & $20^{i}$ & $0.28 \pm 0.05$ & $0.52 \pm 0.03$ & $-0.12 \pm 0.05$ & 0.979 & 192 & 0.54 \\
\hline$t$-BuOCOF & I & $21^{j}$ & $0.49 \pm 0.11$ & $0.69 \pm 0.07$ & $-0.06 \pm 0.08$ & 0.947 & 79 & 0.71 \\
\hline$t$-BuOCOF & I & $17^{j}$ & $0.41 \pm 0.05$ & $0.65 \pm 0.03$ & $0.02 \pm 0.04$ & 0.989 & 301 & 0.63 \\
\hline 1-AdOCOF & A-E & $10^{k}$ & $2.78 \pm 0.21$ & $1.01 \pm 0.06$ & $0.09 \pm 0.16$ & 0.987 & & 2.78 \\
\hline 1-AdOCOF & I & $16^{k}$ & $\sim 0$ & $0.70 \pm 0.01$ & $-0.02 \pm 0.05$ & 0.999 & & $\sim 0$ \\
\hline 1-AdOCOCl & I & $15^{l}$ & $\sim 0$ & $0.47 \pm 0.03$ & $0.03 \pm 0.05$ & 0.985 & 97 & $\sim 0$ \\
\hline EtSCOCl & I & $19^{m}$ & $0.66 \pm 0.08$ & $0.93 \pm 0.07$ & $-0.16 \pm 0.31$ & 0.961 & 96 & 0.71 \\
\hline$i$-PrSCOCl & I & $19^{n}$ & $0.38 \pm 0.11$ & $0.72 \pm 0.09$ & $-0.28 \pm 0.10$ & 0.961 & 97 & 0.53 \\
\hline
\end{tabular}

${ }^{a}$ Addition-elimination(A-E) and ionization(I). ${ }^{b}$ Number of solvent systems included in the correlation. ${ }^{c}$ Using G-W equation with standard errors for $l$ and $m$ values and with the standard errors of the estimate accompanying the c values. ${ }^{d}$ Correlation coefficient. ${ }^{e} F$-test value. ${ }^{f}$ The 22 solvent systems with omission TFE-EtOH (ref. 1(b)). ${ }^{g}$ The 20 solvent systems with omission $90 \%$ HFIP (ref. 1(a)). ${ }^{h}$ All solvent systems (ref. 1 (d)). ${ }^{i}$ The 24 solvent systems with omission of $\mathrm{EtOH}, 90 \% \mathrm{EtOH}, \mathrm{MeOH}$, and $90 \% \mathrm{MeOH}$ (ref. 1(c)). ${ }^{j} \mathrm{All}$ solvent systems $(n=21)$ of this study and the solvent systems with omission of the four TFE-EtOH mixtures $(n=17) .{ }^{k}$ The 26 solvent systems divided into 16 aqueous fluoroalcohol solvents and the remainder (ref. 1(f)). ${ }^{l}$ All solvent systems (ref. 1(e)). ${ }^{m}$ The 22 solvent systems with omission of EtOH, $90 \% \mathrm{EtOH}$, and $\mathrm{MeOH}(\mathrm{ref} .1(\mathrm{~g})) .{ }^{n} \mathrm{The} 20$ solvent systems with omission of $100 \% \mathrm{EtOH}$ (ref. 13). ${ }^{\circ}$ Constant (residual) term.

the specific rates of solvolysis of 1 leads to a poor linear correlation with values of $0.46 \pm 0.05$ for $m,-0.29 \pm 0.09$ for $\mathrm{c}$, and 0.889 for the correlation coefficient. Clearly, this equation does not correlate the data. Except for solvolyses in TFE-ethanol mixtures, $t$-butyl fluoroformate (1) solvolyzes by a reaction channel which, in terms of the extended Grunwald-Winstein equation (eqn. 2), gives values of $0.41 \pm 0.05$ for $l, 0.65 \pm 0.03$ for $m, 0.02 \pm 0.04$ for $\mathrm{c}$, and 0.989 for the correlation coefficient (Figure 1). The results of the correlation are reported in Table 4, together with the corresponding parameters obtained in the analyses of earlier studied substrates. The $l / m$ ratio has been suggested as a useful mechanistic criterion and the values of Table 4 divide nicely into two classes with values of 1.8 to 2.8 for those entries postulated to represent addition-elimination pathway (Scheme 1) and 0.54 to 0.71 for those believed to represent ionization pathway (Scheme 2). The $l / m$ ratio of 0.63 obtained for $\mathbf{1}$ is similar to those previously reported for $i$-PrOCOCl, ${ }^{1(\mathrm{c})} \mathrm{EtSCOCl}^{1}{ }^{1 \mathrm{~g})} i$-PrSCOCl, ${ }^{13}$ and $t$-butyl chloride $(l=0.34 \pm 0.04, m=0.84 \pm 0.02 \text {, and } l / m=0.40)^{14}$ in all solvents except the less ionizing and more nucleophilic solvents, consistent with the unimolecular pathway. The higher $m$-values for the solvolyses of fluoroformates, relative to chloroformates except alkyl chlorothioformates, may reflect the need for increased solvation of the developing positive charge on the carbonyl carbon the presence of the more electronegative fluorine attached at the carbonyl carbon.

\section{Conclusions}

The specific rates of solvolyses of 1 give a satisfactory extended Grunwald-Winstein equation over wide range of $N_{\mathrm{T}}$ and $Y_{\mathrm{Cl}}$ values $(\mathrm{r}=0.989)$. The sensitivities to change in $N_{\mathrm{T}}$ and $Y_{\mathrm{Cl}}$ $(l=0.41 \pm 0.05$ and $m=0.65 \pm 0.03, l / m=0.63$ ) are similar to those for $i$-PrOCOCl, EtSCOCl and $i$-PrSCOCl (Table 3), which have been shown to solvolyze with the bond breaking step of an ionization pathway being rate determining. The solvent deuterium isotope effect value for methanolysis $\left(k_{\mathrm{MeOH}} / k_{\mathrm{MeOD}}\right)$ of 1.26 is typical magnitude of the unimolecular reaction. Four measured values for the entropy of activation for the tert-butyl fluoroformate reaction (1), in the range of -2.8 to $-6.7 \mathrm{cal} \mathrm{mol}^{-1}$ $\mathrm{K}^{-1}$, are consistent with the unimolecular nature of the proposed rate-determining step.

In the present study, the solvolysis of $\mathbf{1}$ is very similar to those analyzed of the specific rates for the solvolyses of $i$-PrOCOCl, EtSCOCl and $i$-PrSCOCl (Table 4) believed to proceed by the ionization pathway (Scheme 2) over the full range of solvent.

\section{Experimental}

$t$-Butyl fluoroformate $\left(\mathbf{1}\right.$, bp $78-80^{\circ} \mathrm{C} / 760 \mathrm{mmHg}$ ) was prepared from $t$-butyl alcohol (Aldrich) via reaction with 1-chloroethyl chloroformate (Aldrich) by a procedure as described earlier. ${ }^{15}$ Solvents were purified and the kinetic runs carried out as previously described. ${ }^{16}$ All runs were performed using a substrate concentration of $5.128 \times 10^{-3} \mathrm{M}$ and with $5 \mathrm{~mL}$ portions removed for titration, but with $2 \mathrm{~mL}$ portions for runs in TFE$\mathrm{H}_{2} \mathrm{O}$ and TFE-EtOH mixtures. The $l$ and $m$ values were calculated using commercially available computer programs for multiple regression analyses.

Acknowledgments. This work was supported by the research fund of Hanyang University (HY-2009-N).

\section{References}

1. (a) Kevill, D. N.; Kim, J. C.; Kyong, J. B. J. Chem. Res. Synop. 1999, 150. (b) Seong, M. H.; Choi, S. H.; Lee, Y. W.; Kyong, J. B.; Kim, D. K.; Kevill, D. N. Bull. Korean Chem. Soc. 2009, 30, 2408. (c) D'Souza, M. J.; Reed, D. N.; Erdman, K. J.; Kyong, J. B.; Kevill, D. N. Int. J. Mol. Sci. 2009, 10, 862. (d) Lee, S. H.; Rhu, C. 
J.; Kyong, J. B.; Kim, D. K.; Kevill, D. N. Bull. Korean Chem. Soc. 2007, 28, 657. (e) Kevill, D. N.; Kyong, J. B.; Weitl, F. L. J. Org. Chem. 1990, 55, 4304. (f) Kevill, D. N.; Kyong, J. B. J. Org. Chem. 1992, 57, 258. (g) Kevill, D. N.; D’Souza, M. J. J. Org. Chem. 1998, 63, 2120. (h) D'Souza, M. J.; Mahon, B. P.; Kevill, D. N. Int. J. Mol. Sci. 2010, 11, 2597.

2. (a) Grunwald, E.; Winstein, S. J. Am. Chem. Soc. 1948, 70, 846. (b) Fainberg, A. H.; Winstein, S. J. J. Am. Chem. Soc. 1956, 78, 2770. (c) Well, P. R. Chem. Rev. 1963, 63, 171.

3. (a) Bentley, T. W.; Carter, G. E. J. Am. Chem. Soc. 1982, 104, 5741. (b) Bentley, T. W.; Llewellyn, G. Prog. Phys. Org. Chem. 1990, 17, 121. (c) Kevill, D. N.; D'Souza, M. J. J. Chem. Res., Synop. 1993, 174. (d) Lomas, J. S.; D’Souza, M. J.; Kevill, D. N. J. Am. Chem. Soc. 1995, 117, 5891.

4. Schleyer, P. v. R.; Nicholas, R. D. J. Am. Chem. Soc. 1961, 83, 2700.

5. Schadt, F. L.; Bentley, T. W.; Schleyer, P. v. R. J. Am. Chem. Soc. 1976, 98, 7667.

6. Kevill, D. N.; Anderson, S. W. J. Org. Chem. 1991, 56, 1845.

7. Kevill, D. N. In Advances in Quantitative Structure-Property Re- lationship; Charton, M., Ed.; JAI Press: Greenwich, CT, 1996; Vol. 1, pp 81-115.

8. (a) Liu, K.-T.; Hou, S.-J.; Tsao, M.-L. J. Org. Chem. 1998, 63, 1360. (b) Liu, K.-T.; Kou, S.-J.; Tsao, M.-L. J. Chin. Chem. Soc. 2009, 56, 425.

9. Choppin, A. R.; Rodgers, J. W. J. Am. Chem. Soc. 1948, 70, 2967.

10. Queen, A. Can. J. Chem. 1967, 45, 1619.

11. Koo, I. S.; Yang, K.; Kang, K.; Lee, I. Bull. Korean Chem. Soc. 1998, 19, 968

12. Kivinen, A. In The Chemistry of Acyl Halides; Patai, S., Ed.; Interscience: New York, 1972; pp 198-200.

13. D'Souza, M. J.; Mahon, B. P.; Kevill, D. N. Int. J. Mol. Sci. 2010, 11, 2597.

14. (a) Kevill, D. N.; D'Souza, M. J. J. Chem. Res. Synop. 1990, 17, 121. (b) Kevill, D. N.; D’Souza, M. J. Cur. Org. Chem. 2010, 14, 1037.

15. Dang, V. A.; Olofson, R. A.; Wolf, P. R.; Piteau, M. D.; Senet, J-P. G. J. Org. Chem. 1990, 55, 1847.

16. Lee, Y. H.; Seong, M. H.; Lee, E. S.; Lee, Y. W.; Won, H.; Kyong, J. B.; Kevill, D. N. Bull. Korean Chem. Soc. 2010, 31, 1209. 